\title{
Isolation of axenic cyanobacterium and the promoting effect of associated bacterium on axenic cyanobacterium
}

\author{
Suqin $\mathrm{Gao}^{1+}$, Yun Kong ${ }^{2,3,4,5+} \mathbb{D}$, Jing Yu', Lihong Miao ${ }^{1 *}$, Lipeng $\mathrm{Ji}^{2}$, Lirong Song ${ }^{6}$ and Chi Zeng ${ }^{1}$
}

\begin{abstract}
Background: Harmful cyanobacterial blooms have attracted wide attention all over the world as they cause water quality deterioration and ecosystem health issues. Microcystis aeruginosa associated with a large number of bacteria is one of the most common and widespread bloom-forming cyanobacteria that secret toxins. These associated bacteria are considered to benefit from organic substrates released by the cyanobacterium. In order to avoid the influence of associated heterotrophic bacteria on the target cyanobacteria for physiological and molecular studies, it is urgent to obtain an axenic M. aeruginosa culture and further investigate the specific interaction between the heterotroph and the cyanobacterium.

Results: A traditional and reliable method based on solid-liquid alternate cultivation was carried out to purify the xenic cyanobacterium M. aeruginosa FACHB-905. On the basis of $16 \mathrm{~S}$ rDNA gene sequences, two associated bacteria named strain B905-1 and strain B905-2, were identified as Pannonibacter sp. and Chryseobacterium sp. with a 99 and $97 \%$ similarity value, respectively. The axenic M. aeruginosa FACHB-905A (Microcystis 905A) was not able to form colonies on $\mathrm{BG}_{11}$ agar medium without the addition of strain $\mathrm{B} 905-1$, while it grew well in $\mathrm{BG}_{11}$ liquid medium. Although the presence of B905-1 was not indispensable for the growth of Microcystis 905A, B905-1 had a positive effect on promoting the growth of Microcystis 905A.

Conclusions: The associated bacteria were eliminated by solid-liquid alternate cultivation method and the axenic Microcystis 905A was successfully purified. The associated bacterium B905-1 has the potentiality to promote the growth of Microcystis 905A. Moreover, the purification technique for cyanobacteria described in this study is potentially applicable to a wider range of unicellular cyanobacteria.
\end{abstract}

Keywords: Microcystis aeruginosa, Bacterial symbioses, Microbial ecology, Heterotrophic bacteria, Promoting effect

\section{Background}

The interactions between phototrophic phytoplankton and heterotrophic bacteria are considered to be an integral part of the algal/cyanobacterial life cycle. For example, diatoms and bacteria coexist in the ocean and coevolve in complex interactions that significantly

\footnotetext{
*Correspondence: ky020241@hotmail.com; Ihmiao2002@aliyun.com

†'Sugin Gao and Yun Kong contributed equally to this work.

'School of Biology and Pharmaceutical Engineering, Wuhan Polytechnic University, Wuhan 430023, Hubei, China

Full list of author information is available at the end of the article
}

modify each other's behavior and ultimately impact biogeochemical cycles [1-3]. This interaction plays an important role in photosynthesis and is therefore crucial for the metabolism of phototrophic phytoplankton. The relations between phototrophic phytoplankton and heterotrophic bacteria are much better understood compared with that between zooplankton and bacteria, and it is generally recognized that there are three different types of phototrophic phytoplankton and heterotrophic bacteria interactions: (i) bacteria and phototrophic phytoplankton form a mutualistic relationship in which 
phytoplankton benefits from bacterial products such as nutrients, whereas bacteria profit from phytoplankton products such as extracellular polymeric substances [4]; (ii) bacteria and phototrophic phytoplankton form an antagonism relationship that the growth of phytoplankton is restricted or inhibited by bacteria through algalbacterial/cyanobacterial-bacterial contact mechanism (direct interaction) or secretion of the extracellular antialgal/anticyanobacterial substances (indirect interaction) $[5,6]$ and (iii) bacteria and phototrophic phytoplankton form a commensal relationship that bacteria are loosely associated with phytoplankton and may promote the growth and photosynthesis without having any negative effect, while phytoplankton grows well without the associated bacteria $[7,8]$. These scenarios may be dependent on the characteristics of phototrophic phytoplankton species, associated bacterial species and secreted substances of the associated heterotrophic bacteria [4].

Harmful cyanobacterial blooms (HCBs) in lakes, reservoirs and rivers have drawn great attention all over the world as microcystin-producing cyanobacteria cause animal and human health concerns [5, 6, 9]. Microcystis aeruginosa, a unicellular, photoautotrophic and gramnegative cyanobacterium that belongs to the genus Microcystis, division Cyanophyta is one of the most common and widespread bloom-forming cyanobacteria that secret toxins $[5,6,10]$. Previous studies show that the cyanobacterium is associated with a large number of bacteria, and these associated heterotrophic bacteria (heterotrophs) are considered to benefit from organic substrates released by the cyanobacterium [11-18]. In order to avoid the influence of heterotrophs for physiological and molecular studies, the purification of the axenic cyanobacterium (bacteria-free) is especially important as well as the understanding of its responses to the heterotrophs.

Various methods including UV irradiation, sonication, micropipette technique, phenol treatment, antibiotic treatment and lysozyme treatment have been used for cyanobacteria purification [19-25]. Previous study shows that treatment with antibiotics is a successful strategy to obtain axenic cyanobacteria cultures [1]. Additionally, solid medium is simple and useful for the growth and isolation of axenic Microcystis strains, in which way two axenic Microcystis strains are obtained [24, 26]. Although the direct and indirect inhibiting effects of bacteria on cyanobacteria have been intensively studied [3, $5,6,12,13,27]$ and the associated bacteria are potentially regarded to regulate cyanobacterium growth via extracellular amino acid monomers or other substances $[5,6]$, the growth-promoting effects of heterotrophs on cyanobacterium have not received much attention. Apart from cyanobacterium purification, the growthpromoting effect of the heterotrophs on cyanobacterium is a significant aspect for understanding the interactions between heterotrophs and cyanobacteria. Therefore, the aim of the present study is to obtain an axenic M. aeruginosa culture and investigate the specific interaction between the heterotrophs and the cyanobacterium.

\section{Results \\ Isolation and purification of the axenic culture}

M. aeruginosa 905 and 907 samples were curated by the Freshwater Algae Culture Collection of Institute of $\mathrm{Hy}$ drobiology (FACHB) as xenic consortia comprised of one $M$. aeruginosa strain and its associated heterotrophic bacteria. The colony forming process of cyanobacterium and heterotrophs on solid plates $\left(\mathrm{BG}_{11}\right.$ agar medium) was observed by inverted phase contrast microscope, and the results were shown in Fig. 1. It is obvious that the heterotrophs colonies were much bigger than the cyanobacterium colonies, indicating the heterotrophs were grew much better compared with cyanobacterium. The cyanobacterium colony was formed when cultured for $15 \mathrm{~d}$, although it was small; moreover, the cyanobacterial colonies were only found in 3 plates among the 20 replicate plates even after incubating for $20 \mathrm{~d}$. Then the isolated cyanobacterial colonies were transferred into 6 test tubes with a Pasteur pipette under the microscope and incubated for $3 \mathrm{~d}$. The result showed that 5 tubes become green, indicating the cyanobacterium grew well. With several cycles of purification, the axenic $M$. aeruginosa FACHB-905A (Microcystis 905A) was obtained. Possible contamination such as heterotrophs was subsequently examined before and after the incubations, and the results revealed that there was no contamination. Then a molecular identification was carried out for the purified axenic cyanobacterium named as Microcystis 905A. The results indicated that Microcystis $905 \mathrm{~A}$ presented the highest sequence similarity (99\% of identity) with $M$. aeruginosa NIES-843, $M$. aeruginosa PCC 7820 and M. aeruginosa PCC 7806.

\section{Identification of associated bacteria}

Two gram-negative bacteria, named B905-1 and B9052, were isolated from the xenic $M$. aeruginosa FACHB905 (Microcystis 905). To identify the bacteria, phylogenetic analyses were performed using the $16 \mathrm{~S}$ rDNA sequences. A total of $1367 \mathrm{bp}$ of each of the two isolated strains was determined, and the $16 \mathrm{~S}$ rDNA gene sequences obtained were subjected to GenBank BLAST search analyses [28]. Strain B905-1 was most closely related to Pannonibacter phragmitetus L-s-R2A-19.4 with a $99 \%$ similarity value, and strain B905-2 was most closely related to Chryseobacterium sp. with a $97 \%$ similarity value. With the same method, the xenic $M$. aeruginosa FACHB-907 (Microcystis 907) was diluted and then plated on the $\mathrm{BG}_{11}$ solid medium. After culturing under 

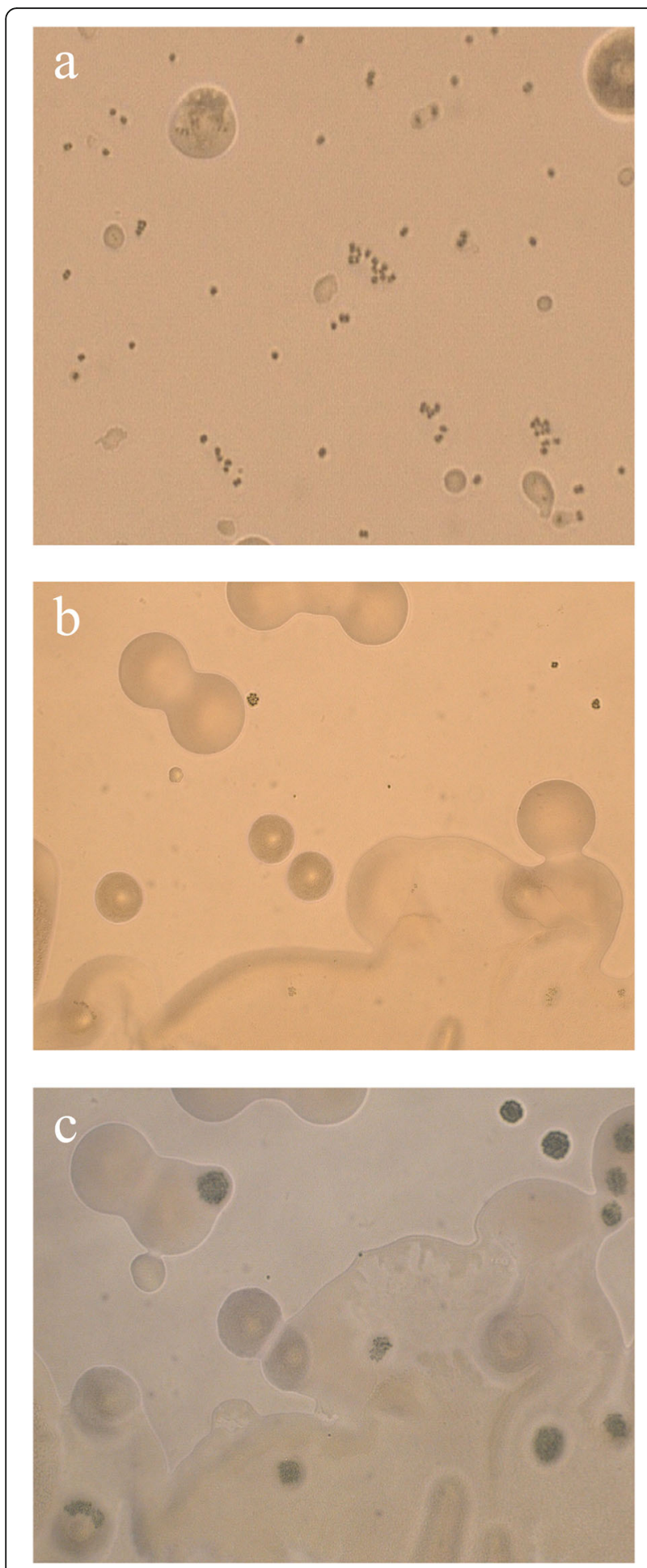

Fig. 1 The growth of cyanobacterial and heterotrophic colonies $(x$ 100). (a, b and $\mathbf{c}$ was the colonial morphology cultured for 1,8 and $15 \mathrm{~d}$, respectively) the culture conditions (Section "Culture of cyanobacteria and heterotrophs") for $15 \sim 20 \mathrm{~d}$, the single cyanobacterial colonies were transferred into test tubes with a Pasteur pipette under the microscope and incubated for $3 \mathrm{~d}$. The results showed that 5 tubes became green, indicating the cyanobacterium grew well. With several cycles of purification, the axenic Microcystis 907A and another heterotroph B907-1 were also successfully isolated, and B907 was identified as Agrobacterium sp., which was most closely related to Agrobacterium sp. PNS-1 and Agrobacterium albertimagni C0008 with a 98\% similarity value. The sequences of $\mathrm{B} 905-1$ and B907-1 were imported into the DNAMAN software V6 and aligned [29]. Phylogenetic tree was then constructed (Fig. 2) and it was further confirmed that strain B905-1 and B907-1 were closely related to Pannonibacter sp. and Agrobacterium sp., respectively.

\section{Effect of associated bacteria on Microcystis 905A}

The growth rates of xenic culture (Microcystis 905) and axenic culture (Microcystis 905A) were measured under both the static cultivation (without the shaking speed) and the shaking cultivation conditions (with the shaking speed of $150 \mathrm{rpm}$ ). Figure 3 indicated that the generation time of axenic culture was $42.3 \mathrm{~h}$ (shaking cultivation) and $60.9 \mathrm{~h}$ (static cultivation), while the generation time of xenic culture was $33.6 \mathrm{~h}$ under the shaking cultivation and $45.3 \mathrm{~h}$ under the static cultivation, respectively. In addition, the generation time of xenic culture was much shorter than that of the axenic culture under the same cultivation condition, which demonstrated the photosynthetic efficiency of Microcystis 905 was much better. At the same time, the growth rates of both the xenic culture and axenic culture under the shaking cultivation condition were much faster than that under the static cultivation condition. These results pointed to the role of the heterotrophs in promoting the growth of Microcystis 905A.

\section{Effect of heterotroph-cyanobacterium ratio on Microcystis 905A}

To further study the effect of heterotroph B905-1 on the growth of axenic Microcystis 905A, a series of experiments that different initial cyanobacterial cell concentrations with the heterotroph-cyanobacterium ratio of 1 : 1, 1:10 and 1:100 were undertaken in $\mathrm{BG}_{11}$ liquid medium (Fig. 4). Compared with the control group (CK), the cyanobacterial cell numbers of 1:1 treatment group was slightly suppressed during the $21 \mathrm{~d}$, while the 1:10 and 1:100 treatment groups showed a remarkable increase, and they were increased with the extension of culture time. In addition, the highest cyanobacterial cell number for the treatment group of 1:10 and 1:100 was $(14.72 \pm 0.48) \times 10^{6}$ cell $\mathrm{mL}^{-1}$ and $(10.63 \pm 0.37) \times 10^{6}$ 


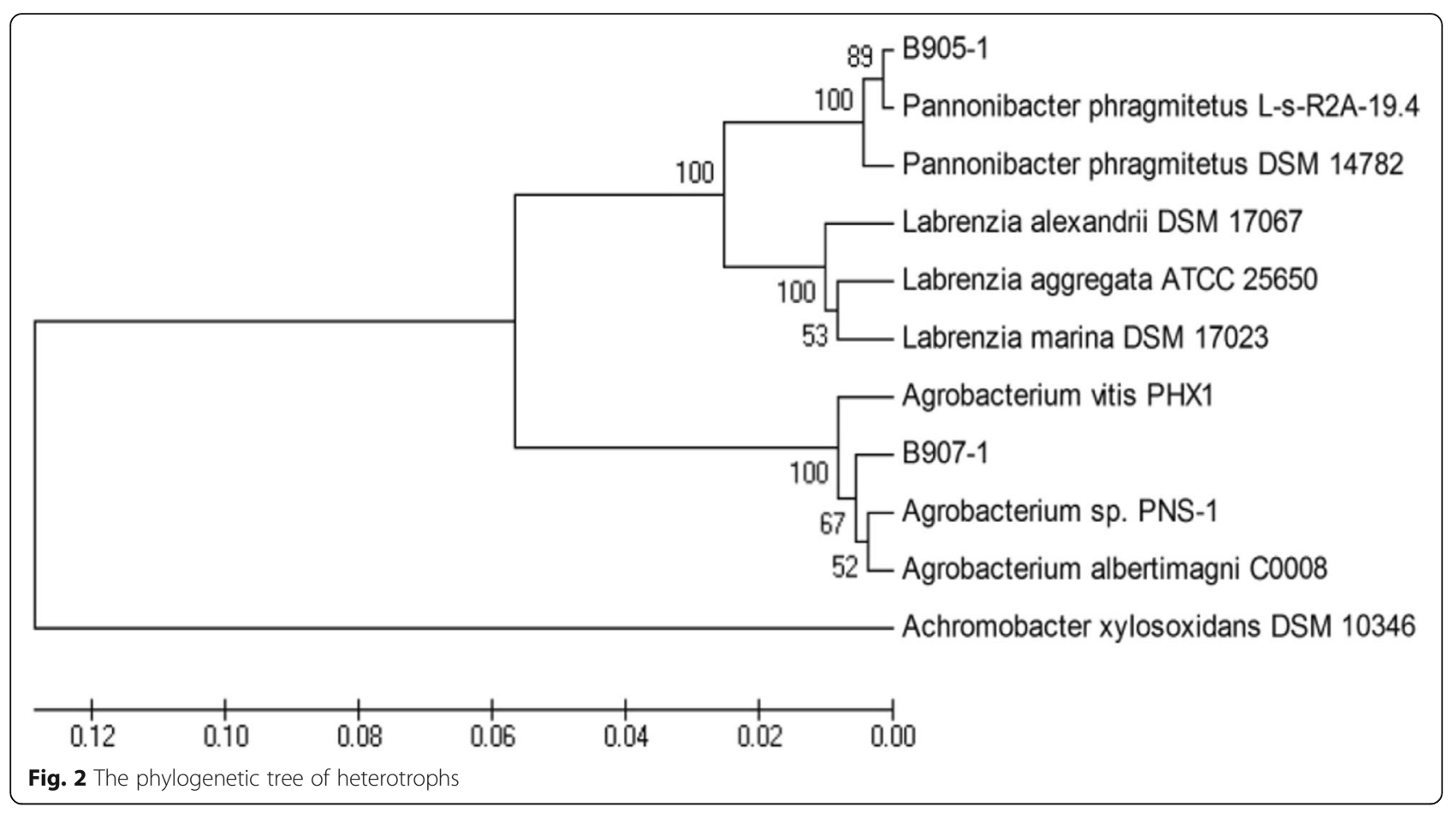

cell $\mathrm{mL}^{-1}$, respectively (Fig. $4 \mathrm{~d}$ ), and both of them were obtained at the 21st day. Obviously, the cyanobacterial cell numbers for the 1:10 treatment group were much higher than that for the 1:100 treatment group under the same conditions, and the reason might due to the higher concentration of the strain B905-1 that added at the beginning of the experiment. These results indicated the addition of heterotroph B905-1 had a positive promoting effect on the growth of Microcystis 905A.

The growth of axenic Microcystis $905 \mathrm{~A}$ on $\mathrm{BG}_{11}$ agar medium with and without the addition of strain B905-1 was also investigated. For the treatments that with the

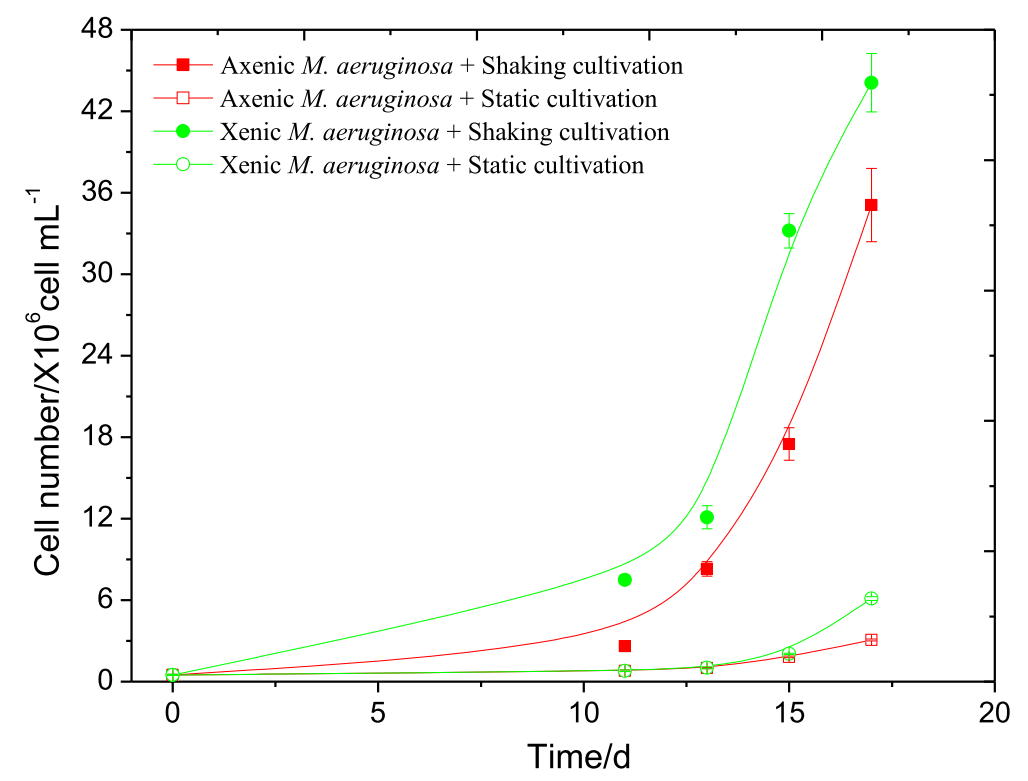

Fig. 3 The growth curves of axenic Microcystis 905A and xenic Microcystis 905 

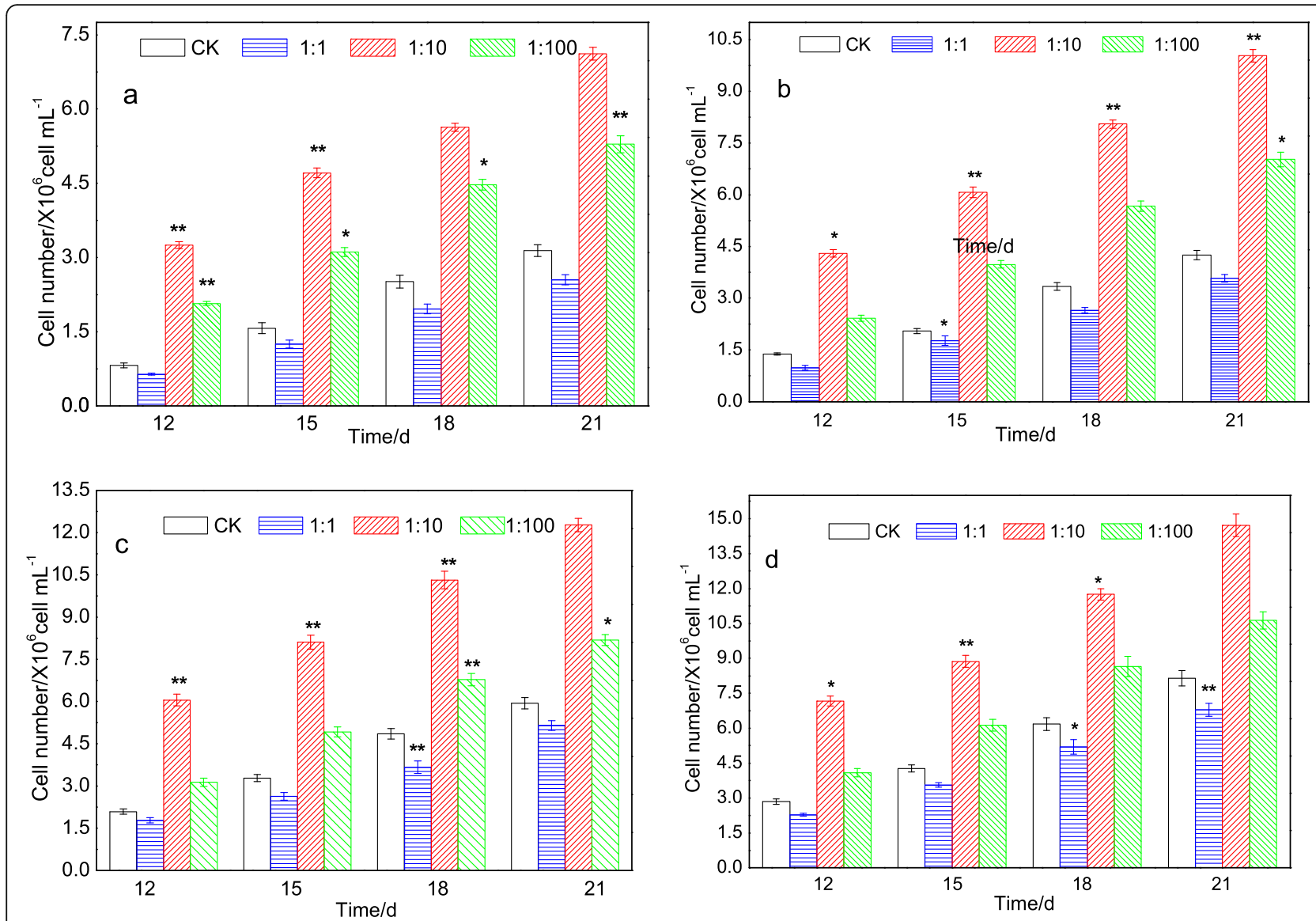

Fig. 4 Effects of heterotroph-cyanobacterium ratio on axenic Microcystis $905 \mathrm{~A}$ (a, b, c and $\mathbf{d}$ showed the initial cyanobacterial cell number of $3.0 \times 10^{2}, 3.0 \times 10^{3}, 3.0 \times 10^{4}$ and $3.0 \times 10^{5}$ cell $\mathrm{mL}^{-1}$, respectively). ${ }^{*}$ and ${ }^{* *}$ represented a statistically significant difference of $p<0.05$ and $p<0.01$ when compared to the control

addition of strain B905-1, the cyanobacterial colony of axenic Microcystis $905 \mathrm{~A}$ became green after incubating for 20 days; while for the treatments that without the addition of strain B905-1, there was no cyanobacterial colony on $\mathrm{BG}_{11}$ agar medium. Moreover, the effects of different heterotroph-cyanobacterium ratio $(1: 1,1: 10$ and 1:100) on the growth of cyanobacterium on $B_{11}$ agar medium were studied (Fig. 5). Interestingly, the Microcystis 905A was unable to grow in the treatment of 1:1 (Fig. 5b), but it grew well in both treatments of 1:10 and 1:100 (Fig. 5c and d). The results indicated high ratio of heterotroph-cyanobacterium (1:1) was not good for the growth of Microcystis 905A, which meant when the initial concentrations of B905-1 and axenic M. aeruginosa were the same, the growth of $M$. aeruginosa on both $\mathrm{BG}_{11}$ liquid medium and $\mathrm{BG}_{11}$ agar medium were inhibited. Previous study showed $\mathrm{BG}_{11}$ could become carbon- or phosphate-limited in dense cultures for some cyanobacteria [30]. The growth of Microcystis 905A was best in the 1:10 condition indicated the C-P ratios influenced by B905-1 were best balanced, where the heterotroph produced an enhancing amount of $\mathrm{CO}_{2}$, but didn't

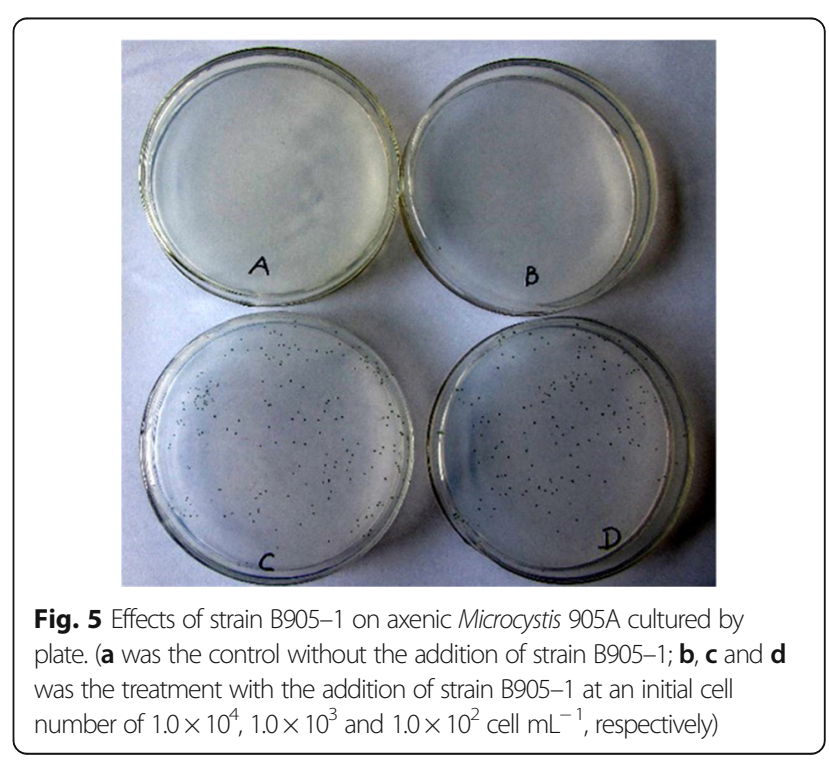


consume too much phosphate in competition with Microcystis 905A.

In order to prove that the promoting effect was associated with the extracellular substances of strain B905-1, the effect of the cell-free filtrate of strain B905-1 on the growth of Microcystis 905A was carried out (Fig. 6). Results showed that the cyanobacterium cell number of the treatment with the addition of the cell-free filtrate was $9.23 \pm 0.56,11.31 \pm 1.85$ and $22.14 \pm 1.06$ cell $\mathrm{mL}^{-1}$ after incubating for $4 \mathrm{~d}, 8$ $\mathrm{d}$ and $12 \mathrm{~d}$, respectively, and it was obviously higher than that with no cell-free filtrate. The axenic cyanobacterium grew much better with the addition of the cell-free filtrate again demonstrating strain B905-1 had the promoting effect on the growth of Microcystis 905A; moreover, the released substances of strain B905-1 with the promoting effect were apparently existed in the cell-free filtrate.

\section{Discussion}

HCBs occur around the world and are responsible for most aquatic environment pollution [9, 10]. Researches of HCBs have been concentrated on the physical, chemical and bio-ecological methods for the control of cyanobacteria and the removal of nitrogen and phosphorous $[5,9]$. Little is known about the microbial community of cyanobacteria with heterotrophs and the interactions between them [2, 3]. Previous studies demonstrated that the oxic cyanobacterial layer of eutrophic water was mainly composed by cyanobacteria and aerobic heterotrophic microorganisms, and the relationships between them were complicated [31, 32]. Therefore, it is necessary to obtain the axenic $M$. aeruginosa from the complex microbial community and further research the interactions between cyanobacteria and heterotrophs.

Traditionally, cyanobacterial purification methods including antibiotic treatment and lysozyme treatment had been applied for eliminating heterotrophs from cyanobacteria and algae [20, 21, 25, 33], and the purification effects were depended on the concentrations and types of antibiotic or lysozyme [22-25]. With a series of antibiotic and lysozyme procedures, the axenic cyanobacteria such as Anabaena flos-aquae, Aphanothece nidulans, Arthrospira platensis and Arthrospira spp. were obtained [22, 23]. While the sensitivities of xenic cyanobacterium Microcystis 905 to five antibiotics employed in the present study are quite different, in particular, four of the tested antibiotics have the inhibition effects on cyanobacterium growth. Furthermore, the lysozyme can inhibit both the cyanobacterium and heterotroph simultaneously (Supporting Information of Table S1 and Fig. S1), it is quite difficult to eliminate the heterotrophs from xenic Microcystis 905 culture by antibiotics treatment or lysozyme treatment methods. Researches indicate the bloom forming cyanobacteria in freshwater or seawater are more often occurred in nutrient-rich environments, and the cyanobacteria are surrounded by diverse communities of heterotrophic bacteria [31, 32, 34]. The difficulty in obtaining the axenic Microcystis 905 is probably due to the lack knowledge of heterotrophs in xenic culture.

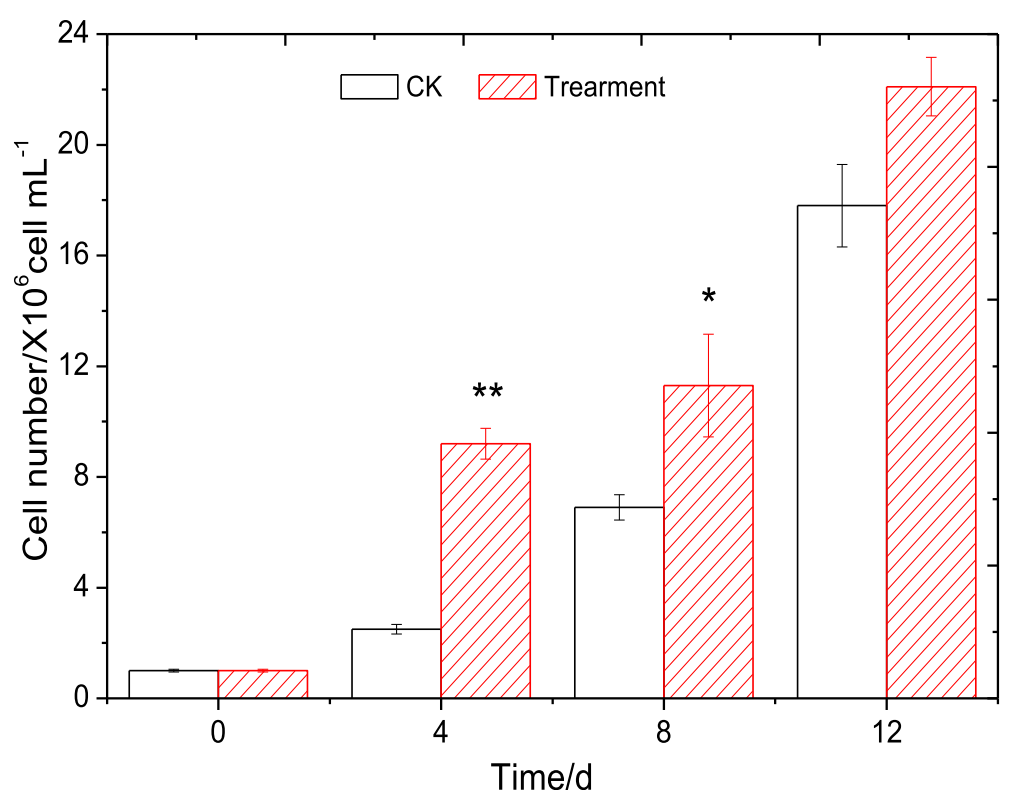

Fig. 6 Effect of cell-free filtrate of strain B905-1 on axenic Microcystis 905A. * and ${ }^{* *}$ represented a statistically significant difference of $p<0.05$ and $p<0.01$ as compared with the control 
Heterotrophs can colonize within the enclosed region or directly adhere to the surface of a cyanobacterium colony [34]. By transferring and culturing xenic culture of Arthrospira platensis in fresh sterile medium, the axenic $A$. platensis is obtained by the technique of single-trichome manipulation performed with a microtrowel [35]. Considering the xenic Microcystis 905 can easily form single cyanobacterial colony on $\mathrm{BG}_{11}$ agar plate and the growth rates of Microcystis and heterotrophs are significantly different, heterotrophs are removed by solid-liquid alternate cultivation method and micropipette technique, which by picking and transferring the single cyanobacterial colony to $\mathrm{BG}_{11}$ liquid medium under the microscope. This method not only guarantees the minimum initial growth density of cyanobacterial cells, but also ensures the purity of cyanobacterial cells, thus results in the successful separation of the axenic Microcystis 905A. It is also successfully applied to purify other strain such as axenic Microcystis 907A. In spite of the traditional standard plate method based on solid-liquid alternate cultivation for obtaining axenic culture is time-consuming, the protocol that we have developed for purifying axenic Microcystis 905A culture maybe suitable for separating axenic strains from a commensal, and potentially syntrophic, symbiosis. These results indicate that this technique is at least applicable to unicellular cyanobacteria.

Molecular biological techniques such as denaturing gradient gel electrophoresis (DGGE) and fluorescence in situ hybridization have been used to investigate the purity of cyanobacterial culture [17, 30]. DGGE results suggest that a number of bacteria including $\alpha$-proteobacteria, $\beta$-proteobacteria, $\gamma$-proteobacteria, Bacteroidetes and Actinobacteria have been detected in the cyanobacterial cultures, and the Sphingomonadales are the prevalent group among the Microcystis-associated bacteria [17]; in another study, the heterotrophs, for instance, Aeromicrobium alkaliterrae, Halomonas desiderata and Staphylococcus saprophyticus are also identified from the Arthrospira platensis culture [25]. The heterotrophic bacteria, such as $\alpha$-proteobacteria and bacteria from the Bacteroidetes-group, are reported to associate with Diatoms in nature as well as in stock cultures [1]. We observe that the heterotrophs strain B905-1 and B905-2 are closely related to Pannonibacter sp. and Chryseobacterium sp., respectively. Besides the identification of heterotrophs, it seems that more attention should be paid to the interactions between heterotrophs and the cyanobacterium $M$. aeruginosa. It is suggested that the interaction between heterotrophs and cyanobacterium is symbiosis or parasitic $[3,36]$, and the heterotrophs are difficult to isolate from cyanobacterium during the formation of cyanobacterial or algal colony [1, 37].

Heterotrophs can enhance or suppress the growth of cyanobacteria, or even kill them [31, 34]. To better understand the general interaction between heterotroph and cyanobacterium, the effect of the strain B905-1 on the cyanobacterium $M$. aeruginosa FACHB-905A is studied. It is showed that the growth rate of the xenic Microcystis 905 is much faster than that of the axenic xenic Microcystis 905A under both static cultivation and shaking cultivation conditions. The results indicate that the heterotroph B905-1 has a promoting effect on the growth of axenic Microcystis 905A. In consideration of the initial cell number of Microcystis 905 is $(2.2 \pm 0.2) \times$ $10^{6}$ cell $\mathrm{mL}^{-1}$ and heterotroph B905-1 is $(0.64 \pm 0.07) \times$ $10^{6}$ cell $\mathrm{mL}^{-1}$, it is not surprising that the growthpromoting effect of the 1:10 treatment is much better than the 1:100 treatment. Interestingly, the Microcystis 905A is unable to form colonies in the 1:1 treatment group on $\mathrm{BG}_{11}$ agar medium. Although $M$. aeruginosa is a kind of photosynthetic bacterium (or autotrophic bacteria) and it grows well under the light with inorganic nutrients, which are supplied by $\mathrm{BG}_{11}$ liquid medium, it is not surprising that axenic Microcystis 905A could not divide at the heterotroph-cyanobacterium ratio of $1: 1$, as the heterotroph B905-1 can effectively compete nutrients with axenic Microcystis 905A.

The growth-promoting effect of heterotrophs on algae has recently been observed in other studies, for example, the growth of toxic dinoflagellate Alexandrium fundyense is promoted substantially by Alteromonas sp. [8], and the attached bacteria provide co-existing for diatom Thalassiosira weissflogii to form transparent exopolymer particles [4]. Interpretation of such phenomenon might be explained by the symbiotic interaction that the bacteria deliver vitamins for algae [38], or the addition of bacteria changes the available nutrient concentration such as extracellular organic carbon or dissolved organic matter $[2,4,14,17,31]$. In a previous study, the growth rate and metabolic products of Shewanella putrfaciens, Brochothrix thermosphacta and Pseudomonas sp. show a remarkable increase no matter cultured individually or in all possible combinations compared to the control cultures [39]. Difference from the above-mentioned microorganisms, axenic diatoms are unable to form biofilm when purified from bacteria [4]. Although the axenic Microcystis 905A grows well under the liquid culture condition, it could not form cyanobacterial colonies on the $\mathrm{BG}_{11}$ agar plate without the addition of strain B9051 , indicating the presence of heterotroph B905-1 is indispensable for the growth of axenic Microcystis 905A on $\mathrm{BG}_{11}$ agar plate. The different growth phenomenon of Microcystis $905 \mathrm{~A}$ in solid and liquid $\mathrm{BG}_{11}$ medium is mainly attributed to the phosphate. It is reported that reactive oxygen species (ROS) were produced when phosphate was autoclaved together with agar, and total colony counts of Gemmatimonas aurantiaca in liquid medium (without agar) were remarkably higher than 
those grown on solid medium (with agar) [40]. In the same way, there may be some ROS produced in $\mathrm{BG}_{11}$ solid medium and the ROS is likely a contributing factor to the growth inhibition of Microcystis 905A. It is speculated that the heterotrophic bacterium B905-1 closely associated with cyanobacterium likely consume nutrients that released by Microcystis 905 , and may also produce vitamins and other beneficial metabolites useful for cyanobacterial growth [32, 34]. Nevertheless, the presence of strain B905-1 for the cyanobacterial colony formation mechanism needs to be further studied.

Previous study also indicates that the enhancement growth of axenic Microcoleus chthonoplastes PCC 7420 is upon the addition of a filtrate obtained from the closely related xenic culture of Microcoleus sp. M2C3, and the stimulated effect could be due to the release of certain growth factors and vitamins by associated aerobic heterotrophic microorganisms [31]. Most of the strains are able to secrete active substance to inhibit or enhance the growth of cyanobacteria [41]. Possible mechanisms may include various types of interactions from nutrient cycling to the production of growthinhibiting and cell-lysing compounds [42]. Our results demonstrate that strain B905-1 has the potential to promote Microcystis 905A growth, whereas Microcystis 905A provides organic matter for associated bacterial proliferation. In a comparable study it is pointed out that bacteria have the potential to control diatom growth, and their interactions are regulated by multiple signals involving common biomolecules such as proteins, polysaccharides and respective monomers [14]. In accordance with previous observations, we also find the associated bacterium has promoting effect on the growth of cyanobacterium $M$. aeruginosa. Increasing knowledge on molecular mechanisms of microbial interactions are crucial to better understand or predict nutrient and organic matter cycling in aquatic environment, and also to better understand the role of such associated bacterium for the formation mechanism of HCBs and eutrophication control.

Up to now, most studies on the interaction between heterotrophs and cyanobacteria are performed in pure cultures [32, 34, 41], and the growth of the axenic cyanobacteria is almost promoted by the heterotrophs $[8,32,34]$. However, the interaction can be profoundly different in nature, as most microbes are not axenic but grow together in communities. The complex communities or microbial networks often result in surprisingly coordinated multicellular behaviour, e.g. dinoflagellates can feed on associated bacteria and heterotrophs also attack and lysis the cyanobacteria [31]. Furthermore, the heterotrophs are considered as playing a significant role in carbon cycling and cyanobacterial photosynthesis [31]. All these studies suggest that the relationship between heterotrophs and cyanobacteria in nature is complex and manifold, further analysis is needed to have a full understanding of the microbial communities surrounding cyanobacteria.

\section{Conclusions}

Our results showed that heterotrophs were eliminated by solid-liquid alternate cultivation method and the axenic Microcystis 905A was successful purified by means of picking and transferring the single cyanobacterial colony to $\mathrm{BG}_{11}$ liquid medium under the microscope; moreover, two heterotrophs, strain B905-1 and strain B905-2, were identified as Pannonibacter sp. and Chryseobacterium sp. with a 99 and $97 \%$ similarity value in the basis of $16 \mathrm{~S}$ rDNA gene sequences. Further, strain B905-1 had the potentiality to promote the growth of Microcystis 905A. The purification technique for cyanobacteria described in this study is potentially applicable to a wider range of unicellular cyanobacteria.

\section{Methods \\ Culture of cyanobacteria and heterotrophs}

Xenic Microcystis 905 and Microcystis 907 used in this study were purchased from the FACHB, Chinese Academy of Sciences (Wuhan, China). Sterilized BG 11 liquid medium or $\mathrm{BG}_{11}$ agar medium (with the agar concentration of $1.5 \%$ ) was used as the main culture medium for both axenic and xenic $M$. aeruginosa [5, 6, 43]. Before being used as inoculants, cyanobacteria were cultured with $200 \mathrm{~mL} \mathrm{BG}{ }_{11}$ liquid medium in $500 \mathrm{~mL}$ Erlenmeyer flasks for 7 days to reach the log phase, and the culture conditions were as follows: $2000 \mathrm{~lx}$ white light, light: dark $=14 \mathrm{~h}: 10 \mathrm{~h} ; 25 \pm 1{ }^{\circ} \mathrm{C}[5,6]$. Axenic Microcystis 905A was obtained by treating with micro-picking from Microcystis 905 culture.

Bacterial strains B905-1 and B905-2 were isolated from the culture solution of the cyanobacterium Microcystis 905 . These two bacteria were routinely grown in TY liquid medium [44] at $28 \pm 1{ }^{\circ} \mathrm{C}$ under aerobic conditions (with the shaking speed of $150 \mathrm{rpm}$ ). The cell-free filtrate of strain B905-1 was obtained by centrifuging the fermentation broth at $10,000 \times \mathrm{g}$ for $10 \mathrm{~min}$ and then filtered through with the $0.22 \mu \mathrm{m}$ cellulose acetate membrane [5]. Stock cultures were kept at $4{ }^{\circ} \mathrm{C}$, and working cultures were obtained from stock cultures through two transfers in appropriate TY liquid medium.

\section{Isolation and purification of axenic culture}

For the isolation and purification of axenic cultures, cyanobacterial cells were treated by the solid-liquid alternate cultivation method. The xenic cyanobacterium was diluted to different multiple from $10^{-1}$ to $10^{-8}$, and the different multiple were inoculated onto sterile Petri dishes containing $\mathrm{BG}_{11}$ agar medium, respectively [45]. 
After incubating for 15 to $20 \mathrm{~d}$ under the culture conditions above, a single cyanobacterial colony was picked by a Pasteur pipette with the aid of a microscope, and then transferred into a test tube that containing $5 \mathrm{~mL} \mathrm{BG}_{11}$ liquid medium. The purification result was checked as the test tube becoming green, and the testing method was as follows: $0.1 \mathrm{~mL}$ cyanobacterial culture from the test tube was spread on the Luria-Bertani (LB) agar plate $[44,46]$ and incubated at room temperature for $3 \mathrm{~d}$ or more to examine the existence of heterotrophs, the absence of heterotrophs indicated this cyanobacterial culture was axenic. After the purification, the axenic cyanobacterial colony was picked up by a Pasteur pipette, then transferred to Erlenmeyer flasks with $\mathrm{BG}_{11}$ liquid medium, and incubated at $25 \pm 1{ }^{\circ} \mathrm{C}$ in a $14 \mathrm{~L} / 10 \mathrm{D}$ light-dark cycle. The purification procedure for axenic Microcystis was illustrated in Fig. 7.

\section{Cyanobacterial inhibition bioassay}

The growth curve of axenic Microcystis 905A and xenic Microcystis 905 were carried out at an initial cyanobacterial cell number of $1.0 \times 10^{6}$ cell $\mathrm{mL}^{-1}$. Effects of heterotroph-cyanobacterium ratio on the growth of four kinds of different initial axenic cyanobacterial cell concentrations in $\mathrm{BG}_{11}$ liquid medium were performed as follows: the axenic Microcystis 905A was firstly added in $250 \mathrm{~mL}$ sterilized Erlenmeyer flasks containing $100 \mathrm{~mL}$ $\mathrm{BG}_{11}$ liquid medium to keep the cyanobacterial cell number of $3.0 \times 10^{2}, 3.0 \times 10^{3}, 3.0 \times 10^{4}$ and $3.0 \times 10^{5}$ cell $\mathrm{mL}^{-1}$, respectively, and then strain B905-1 (initial cell number was $2.73 \times 10^{7}$ cell $\mathrm{mL}^{-1}$ ) was added according to heterotroph-cyanobacterium ratio of $1: 1,1: 10$ and 1 : 100 , the controls (CK) were without the addition of strain B905-1. For the effects of heterotrophcyanobacterium ratio on the growth of axenic Microcystis $905 \mathrm{~A}$ on $\mathrm{BG}_{11}$ agar medium, the heterotroph (B9051) and cyanobacterium (axenic $M$. aeruginosa) were mixed well in $\mathrm{BG}_{11}$ liquid medium, and the final heterotroph-cyanobacterium ratios of 1:1, 1:10 and 1:100 were performed by adding different amounts of bacterium into the $100 \mathrm{~mL}$ axenic $M$. aeruginosa culture with the initial cyanobacterial cell number of $1.0 \times 10^{4}$ cell $\mathrm{mL}^{-1}$. The mixed suspensions were diluted to different multiples and then plated on the $\mathrm{BG}_{11}$ agar medium, each dilution gradient was repeated for three times.

The effect of cell-free filtrate of strain B905-1 on axenic Microcystis 905A was carried out by adding the cell-free filtrate $(2 \%, \mathrm{v} / \mathrm{v})$ into a $100 \mathrm{~mL}$ sterilized Erlenmeyer flask which containing initial axenic cyanobacterial cell number of $1.0 \times 10^{6}$ cell $\mathrm{mL}^{-1}$. The cell-free filtrate was obtained by filtrating with the $0.22 \mu \mathrm{m}$ cellulose acetate membrane. The negative control was made by adding the same amount of TY liquid medium into $100 \mathrm{~mL}$ cyanobacterial culture or $\mathrm{BG}_{11}$ agar plate.

All the experiments were performed under aseptic conditions, the controls $(\mathrm{CK})$ and the treatments were

Isolation of cyanobacterial colony using micropipette

Cultivation on BG11 agar medium for $20 \mathrm{~d}$

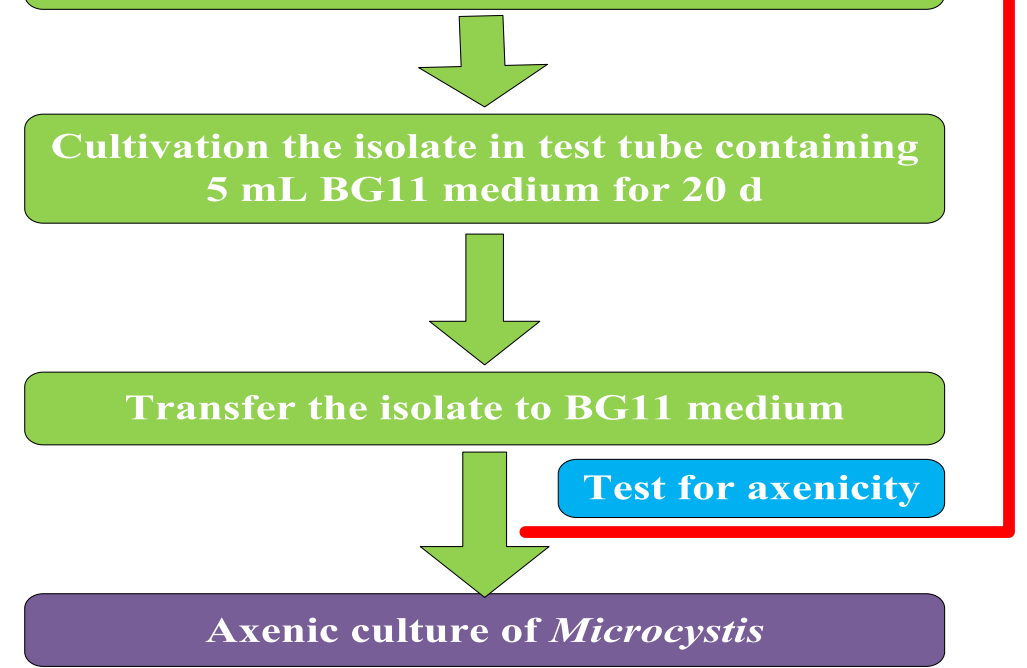

Fig. 7 Purification procedure for axenic culture of Microcystis 
replicated three times, and the arithmetical means ( \pm $\mathrm{SD})$ were used as the final results.

\section{DNA extraction, sequencing and phylogenetic analysis} The isolated bacterial strains were identified based on $16 \mathrm{~S}$ rRNA gene sequence analysis. Heterotrophs were prepared by incubating the seed culture at $37^{\circ} \mathrm{C}$ with a shaking speed of $180 \mathrm{rpm}$ for $20 \mathrm{~h}$ in sterilized LB liquid medium. The heterotroph cells were collected by centrifugation at $4000 \mathrm{rpm}$ for $10 \mathrm{~min}\left(\right.$ at $4{ }^{\circ} \mathrm{C}$ ). DNA was extracted from the bacterial sample using the 3S DNA Isolation Kit V2.2 (Biocolor BioScience \& Technology Co., Shanghai, China). Fragments of the 16S rDNA were amplified by PCR using the primers 27F ( $5^{\prime}$-GAGT TTGATCCTGGCTCAG-3') and 1492R (5'-ACGGCT ACCTTGTTACGACTT-3'), and the amplified fragments were sequenced by AuGCT Biotech Co., Ltd. (Beijing, China) [17]. The BLAST procedure was used to search for sequence similarity in GenBank [28].

\section{Analysis methods}

Bacteria cell density is determined by colony counting method. Samples are cultured on TY agar medium at $28 \pm 1{ }^{\circ} \mathrm{C}$ for $48 \mathrm{~h}$, and the colonies are counted. The cyanobacterium cell number is determined by hemocytometer using light microscopy (NIKON-YS100). The cell density or cell number of each sample is counted in triplicate, and standard error of the mean is calculated for all data. Statistical analysis is performed using Version 17.0 of SPSS for Windows (SPSS, Chicago, IL, USA) [6].

The generation time $(\mathrm{G})$ of the cyanobacterium is calculated according to eq. (1):

$$
\mathrm{G}=\left(\mathrm{t}_{2}-\mathrm{t}_{1}\right) /\left[3.322\left(\lg \mathrm{X}_{2}-\lg \mathrm{X}_{1}\right)\right]
$$

where $X_{1}$ and $X_{2}$ are the cyanobacterium cell number at time $t_{1}$ and $t_{2}$, respectively. (2):

The inhibition efficiency is calculated according to eq.

$$
\text { Inhibition efficiency }=\left(1-C_{t} / C_{0}\right) \times 100 \%
$$

where $\mathrm{C}_{0}$ and $\mathrm{C}_{\mathrm{t}}$ are the cyanobacterium cell number of the control and test group at time $t$, respectively $[5,6]$.

\section{Supplementary Information}

The online version contains supplementary material available at https://doi. org/10.1186/s12896-020-00656-5.

Additional file 1: Table S1. Effects of antibiotics on heterotrophs and cyanobacterium. Figure S1. Effects of lysozyme on heterotrophs and Microcystis 905

\section{Abbreviations}

HCBs: Harmful cyanobacterial blooms; Microcystis 905A: The axenic M. aeruginosa FACHB-905A; Microcystis 907A: The axenic M. aeruginosa FACHB-
907A; Microcystis 905: The xenic M. aeruginosa FACHB-905; Microcystis 907: The xenic M. aeruginosa FACHB-907; FACHB: Freshwater Algae Culture Collection of Institute of Hydrobiology; DGGE: Denaturing gradient gel electrophoresis

\section{Acknowledgments}

We would like to express deep thanks to the Editors and the anonymous reviewers for their helpful comments on the manuscript.

\section{Authors' contributions}

YK and LM conceived and designed the project. SG, JY, LJ and CZ performed the experiments. YK, LM and LS analyzed the data. LM, CZ and LS contributed reagents/materials/analysis tools. YK, SG and LM wrote the paper. All authors have read and approved the manuscript.

\section{Funding}

This study was financially supported by a grant from National High Technology Research and Development Program of China (863 Program) (No.2013AA102805-04), the Key Laboratory of Water Pollution Control and Environmental Safety of Zhejiang Province (No. 2018ZJSHKF06), the Key Project of Jingzhou Science and Technology (No. 2019EC61-15), China Postdoctoral Science Foundation funded project (No. 2016 M591832), the Natural Science Foundation of Jiangsu Province (No. BK20150165) and the Science and Technology Program of Administration of Quality and Technology Supervision of Jiangsu Province (No. KJ15ZB01).

\section{Availability of data and materials}

The data are presented within the manuscript and the cyanobacteria such as M. aeruginosa FACHB-905 and FACHB-907 used in this study could be purchased from the Freshwater Algae Culture Collection of Institute of Hydrobiology (FACHB), Chinese Academy of Sciences (Wuhan, China).

\section{Ethics approval and consent to participate}

This manuscript doesn't involve any human participants, human data, human tissue, individual person's data or animal experiment.

\section{Consent for publication}

Not Applicable.

\section{Competing interests}

The authors declare that they have no competing interests.

\section{Author details}

${ }^{1}$ School of Biology and Pharmaceutical Engineering, Wuhan Polytechnic University, Wuhan 430023, Hubei, China. ${ }^{2}$ College of Resources and Environment, Yangtze University, Wuhan 430100, Hubei, China. ${ }^{3}$ Key Laboratory of Water Pollution Control and Environmental Safety of Zhejiang Province, Hangzhou 310058, Zhejiang, China. ${ }^{4}$ Yixing Academy of Environmental Protection, Nanjing University, Yixing 214200, Jiangsu, China ${ }^{5}$ Yixing Urban Supervision \& Inspection Administration of Product Quality, National Supervision \& Inspection Center of Environmental Protection Equipment Quality (Jiangsu), Yixing 214205, Jiangsu, China. ${ }^{6}$ Institute of Hydrobiology, Chinese Academy of Sciences, Wuhan 430072, Hubei, China.

Received: 13 January 2020 Accepted: 16 November 2020 Published online: 30 November 2020

\section{References}

1. Bruckner CG, Kroth PG. Protocols for the removal of bacteria from freshwater benthic diatom cultures. J Phycol. 2009;45:981-6.

2. Bruckner CG, Rehm C, Grossart HP, Kroth PG. Growth and release of extracellular organic compounds by benthic diatoms depend on interactions with bacteria. Environ Microbiol. 2011:13:1052-63.

3. Amin SA, Parker MS, Armbrust EV. Interactions between diatoms and Bacteria. Microbiol Mol Biol Rev. 2012;76:667-84.

4. Gardes A, Iversen MH, Grossart HP, Passow U, Ullrich MS. Diatom-associated bacteria are required for aggregation of Thalassiosira weissflogii. ISME J. 2011:5:436-45.

5. Kong Y, Zou P, Yang Q, Xu XY, Miao LH, Zhu L. Physiological responses of Microcystis aeruginosa under the stress of antialgal actinomycetes. J Hazard Mater. 2013;262:274-80. 
6. Kong Y, Xu XY, Zhu L. Cyanobactericidal effect of Streptomyces sp. HJC-D1 on Microcystis auruginosa. PLoS One. 2013;8:e57654.

7. Ahmad F, Ahmad I, Khan MS. Screening of free-living rhizospheric bacteria for their multiple plant growth promoting activities. Microbiol Res. 2008;163: 173-81.

8. Ferrier $\mathrm{M}$, Martin $\mathrm{JL}$, Rooney-Varga JN. Stimulation of Alexandrium fundyense growth by bacterial assemblages from the bay of Fundy. J Appl Microbiol. 2002:92:706-16.

9. Chen W, Song LR, Peng L, Wan N, Zhang XM, Gan NQ. Reduction in microcystin concentrations in large and shallow lakes: water and sedimentinterface contributions. Water Res. 2008;42:763-73.

10. Gan NQ, Xiao Y, Zhu L, Wu ZX, Liu J, Hu CL, et al. The role of microcystins in maintaining colonies of bloom-forming Microcystis spp. Environ Microbiol. 2012;14:730-42.

11. Alex A, Vasconcelos V, Tamagnini P, Santos A, Antunes A. Unusual symbiotic cyanobacteria association in the genetically diverse intertidal marine sponge Hymeniacidon perlevis (Demospongiae, Halichondrida). PLoS One. 2012; : 551834

12. Brunberg AK. Contribution of bacteria in the mucilage of Microcystis spp. (cyanobacteria) to benthic and pelagic bacterial production in a hypereutrophic lake. FEMS Microbiol Ecol. 1999:29:13-22.

13. Erwin PM, Olson JB, Thacker RW. Phylogenetic diversity, host-specificity and community profiling of sponge-associated bacteria in the northern Gulf of Mexico. PLoS One. 2011;6:e26806

14. Grossart HP, Czub G, Simon M. Algae-bacteria interactions and their effects on aggregation and organic matter flux in the sea. Environ Microbiol. 2006; 8:1074-84.

15. Grossart HP, Kiorboe T, Tang KW, Allgaier M, Yam EM, Ploug H. Interactions between marine snow and heterotrophic bacteria: aggregate formation and microbial dynamics. Aquat Microb Ecol. 2006;42:19-26.

16. Paerl HW, Bebout BM, Prufert LE. Bacterial association with marine Oscillatoria sp. (Trichodesmium sp.) populations: ecophysiological implications. J Phycol. 1989;25:773-84.

17. Shi LM, Cai YF, Yang HL, Xing P, Li PF, Kong LD, et al. Phylogenetic diversity and specificity of bacteria associated with Microcystis aeruginosa and other cyanobacteria. J Environ Sci China. 2009;21:1581-90.

18. Worm J, Sondergaard M. Dynamics of heterotrophic bacteria attached to Microcystis spp. (cyanobacteria). Aquat Microb Ecol. 1998:14:19-28.

19. Ferris MJ, Hirsch CF. Method for isolation and purificarion of cyanobacteria. Appl Environ Microbiol. 1991:57:1448-52.

20. Han AW, Oh KH, Jheong WH, Cho YC. Establishment of an axenic culture of microcystin-producing Microcystis aeruginosa isolated from a Korean reservoir. J Microbiol Biotechnol. 2010;20:1152-5.

21. Katoh H, Furukawa J, Tomita-Yokotani K, Nishi Y. Isolation and purification of an axenic diazotrophic drought-tolerant cyanobacterium, Nostoc commune, from natural cyanobacterial crusts and its utilization for field research on soils polluted with radioisotopes. BBA Bioenerg. 1817;2012:1499-505.

22. Kim JS, Park YH, Yoon BD, Oh HM. Establishment of axenic cultures of Anabaena flos-aquae and Aphanothece nidulans (cyanobacteria) by lysozyme treatment. J Phycol. 1999;35:865-9.

23. Sena L, Rojas D, Montiel E, Gonzalez H, Moret J, Naranjo L. A strategy to obtain axenic cultures of Arthrospira spp. cyanobacteria. World J Microbiol Biotechnol. 2011:27:1045-53.

24. Shirai M, Matumaru K, Ohotake A, Takamura Y, Aida T, Nakano M. Development of a solid medium for growth and isolation of axenic microcystin strain (cyanobacteria). Appl Environ Microbiol. 1989;55:2569-71.

25. Choi GG, Bae MS, Ahn CY, Oh HM. Induction of axenic culture of Arthrospira (Spirulina) platensis based on antibiotic sensitivity of contaminating bacteria. Biotechnol Lett. 2008;30:87-92.

26. Shirai M, Ohtake A, Sano T, Matsumoto S, Sakamoto T, Sato A, et al. Toxicity and toxins of natural blooms and isolated strains of Microcystis spp. (cyanobacteria) and improved procedure for purification of cultures. Appl Environ Microbiol. 1991;57:1241-5.

27. Casamatta DA, Wickstrom CE. Sensitivity of two disjunct bacterioplankton communities to exudates from the cyanobacterium Microcystis aeruginosa Kutzing. Microb Ecol. 2000;40:64-73.

28. Xu XT, Dimitrov D, Rahbek C, Wang ZH. NCBI miner: sequences harvest from Genbank. Ecography. 2015;38:426-30

29. Peng ZY, Li L, Yang LQ, Zhang B, Chen G, Bi YP. Overexpression of peanut diacylglycerol acyltransferase 2 in Escherichia coli. PLoS One. 2013;8(4): e61363.
30. Kim HW, Vannela R, Zhou C, Rittmann BE. Nutrient acquisition and limitation for the photoautotrophic growth of Synechocystis sp. PCC6803 as a renewable biomass source. Biotechnol Bioeng. 2011;108(2):277-85.

31. Abed RMM, Kohls K, Leloup J, de Beer D. Abundance and diversity of aerobic heterotrophic microorganisms and their interaction with cyanobacteria in the oxic layer of an intertidal hypersaline cyanobacterial mat. FEMS Microbiol Ecol. 2018;94(2):1-12.

32. Cummings SL, Barbé D, Leao TF, Korobeynikov A, Engene N, Glukhov E, et al. A novel uncultured heterotrophic bacterial associate of the cyanobacterium Moorea producens JHB. BMC Microbiol. 2016;16:198

33. Bolch CJS, Blackburn SI. Isolation and purification of Australian isolates of the toxic cyanobacterium Microcystis aeruginosa Kutz. J Appl Phycol. 1996;8: 5-13.

34. Kim M, Shin B, Lee J, Park HY, Park W. Culture-independent and culturedependent analyses of the bacterial community in the phycosphere of cyanobloom-forming Microcystis aeruginosa. Sci Rep. 2019;9(1):20416.

35. Shiraishi H. Association of heterotrophic bacteria with aggregated Arthrospira platensis exopolysaccharides: implications in the induction of axenic cultures. Biosci Biotechnol Biochem. 2015;79(2):331-41.

36. Jasti S, Sieracki ME, Poulton NJ, Giewat MW, Rooney-Varga JN. Phylogenetic diversity and specificity of bacteria closely associated with Alexandrium spp. and other phytoplankton. Appl Environ Microbiol. 2005;71:3483-94.

37. Castenholz RW. Culturing methods for cyanobacteria. Method Enzymol. 1998:167:68-93.

38. Croft MT, Lawrence AD, Raux-Deery E, Warren MJ, Smith AG. Algae acquire vitamin B-12 through a symbiotic relationship with bacteria. Nature. 2005; 438:90-3.

39. Tsigarida E, Boziaris IS, Nychas GJE. Bacterial synergism or antagonism in a gel cassette system. Appl Environ Microbiol. 2003;69:7204-9.

40. Tanaka T, Kawasaki K, Daimon S, Kitagawa W, Yamamoto K, Tamaki H, et al. A hidden pitfall in the preparation of agar media undermines microorganism cultivability. Appl Environ Microbiol. 2014;80(24):7659-66.

41. Zhou Y, Eustance E, Straka L, Lai YJS, Xia SQ, Rittmann BE. Quantification of heterotrophic bacteria during the growth of Synechocystis sp. PCC 6803 using fluorescence activated cell sorting and microscopy. Algal Res. 2018:30:94-100.

42. Berg KA, Lyra C, Sivonen K, Paulin L, Suomalainen S, Tuomi P, et al. High diversity of cultivable heterotrophic bacteria in association with cyanobacterial water blooms. ISME J. 2009;3(3):314-25.

43. Kong $Y, X u X Y$, Zhu L, Miao LH. Control of the harmful alga Microcystis aeruginosa and absorption of nitrogen and phosphorus by Candida utilis. Appl Biochem Biotechnol. 2013;169:88-99.

44. Julkowska D, Obuchowski M, Holland IB, Seror SJ. Comparative analysis of the development of swarming communities of Bacillus subtilis 168 and a natural wild type: critical effects of surfactin and the composition of the medium. J Bacteriol. 2005;187:65-76.

45. Taniuchi Y, Chen YLL, Chen HY, Tsai ML, Ohki K. Isolation and characterization of the unicellular diazotrophic cyanobacterium group C TW3 from the tropical western Pacific Ocean. Environ Microbiol. 2012;14: $641-54$.

46. Sezonov G, Joseleau-Petit D, D'Ari R. Escherichia coli physiology in LuriaBertani broth. J Bacteriol. 2007;189:8746-9.

\section{Publisher's Note}

Springer Nature remains neutral with regard to jurisdictional claims in published maps and institutional affiliations.

Ready to submit your research? Choose BMC and benefit from:

- fast, convenient online submission

- thorough peer review by experienced researchers in your field

- rapid publication on acceptance

- support for research data, including large and complex data types

- gold Open Access which fosters wider collaboration and increased citations

- maximum visibility for your research: over $100 \mathrm{M}$ website views per year

At $\mathrm{BMC}$, research is always in progress.

Learn more biomedcentral.com/submissions 